\title{
Cartografia através de modelos táteis: uma contribuição ao ensino de deficientes visuais
}

\author{
Cleomar Graef de Oliveira* \\ Donarte Nunes dos Santos Júnior** \\ Regis Alexandre Lahm***
}

\begin{abstract}
Resumo
O presente artigo meandra entre um relato de pesquisa, um ensaio teórico e uma revisão de literatura na área da cartografia tátil; ramo da cartografia especializado na confecção de produtos cartográficos para deficientes visuais. Assim, no presente texto, os pesquisadores do LTIG/ PUCRS partilham seus entendimentos acerca da construção de representações espaciais táteis, expondo ideias, críticas e reflexões éticas envolvidas em tais atividades, bem como, ao longo da explanação, revisam a literatura específica disponível atualmente. Os autores defendem o retorno ao concreto como condição de possível abandono de um mundo cada vez mais propenso à homogeneidade e à aplainação.
\end{abstract}

Palavras-chave: Cartografia tátil. Deficientes visuais. Percepção.

\section{Cartography through tactile models: a contribution to the teaching of vision disabled people}

\begin{abstract}
This article streams between a research report, a theoretical essay and a literature review in the field of tactile cartography, which is specialized in the manufacturing of cartographic products for people with a vision disability. Thus, in this text, the LTIG/PUCRS researchers long for sharing their knowledge on the construction of tactile spatial representations, expressing ideas, critique and ethical reflection involved in such activities, as well as, along the explanation, they review the specific literature presently available. The authors defend the return to the concrete as a possible abandon condition of a world more and more predisposed to homogeneity and flatness.
\end{abstract}

Keywords: Tactile cartography. Vision disabled people. Perception.

\footnotetext{
* Acadêmico de Geografia, Pontifícia Universidade Católica de Porto Alegre, Porto Alegre, Rio Grande do Sul, Brasil.

** Professor mestre em Educação em Ciências e Matemática e mestrando em Filosofia, Pontíficia Universidade Católica de Porto Alegre, Porto Alegre, Rio Grande do Sul, Brasil.

*** Professor Doutor em Recursos Hídricos, Universidade Federal do Rio Grande do Sul, Porto Alegre, Rio Grande do Sul, Brasil.
} 


\section{Introdução}

Produtos cartográficos, ${ }^{1}$ sejam eles mais bem elaborados, tais como mapas e/ou cartas militares e topográficas; sejam eles mais arcaicos, tais como, inscrições cuneiformes e/ou pinturas rupestres, confundem-se com a história da humanidade. Isso, já de início, encaminha a um entendimento que vai ao encontro da noção que, grosso modo, o senso comum tem hoje acerca de o que seja um mapa. Por outras palavras, para a maioria das pessoas, um mapa é, invariavelmente, uma representação do $E s p a c ̧ o^{2}$ feita necessariamente de papel. A maior parte dos estudantes da Educação Básica, por exemplo, associa o mapa, qualquer que seja ele, ao $\operatorname{Atlas}^{3}$ escolar.

Esse entendimento, no entanto, não corresponde estritamente à verdade e, como veremos adiante, é ele mesmo que serve de base para preconceitos que acabam por excluir as pessoas com deficiência visual de uma compreensão espacial mais rica e plena. É, de certo modo, a falta de conhecimento cartográfico que contribui para a construção da atual sociedade videntocêntrica. ${ }^{4}$

Ao encontro do entendimento que diz que um mapa não precisa ser sempre de papel, a Arqueologia nos ensina que ele pode ser feito com uma rica variedade de materiais, diversificando-se conforme a cultura e os recursos empregados por cada povo e sociedade. Assim, quem visita o The British Museum (Museu Britânico de Londres) tem a oportunidade de se deparar com uma pequena placa de argila $(12,5 \mathrm{~cm} \times 8,2 \mathrm{~cm})$ que representa o mundo conhecido até então pelos babilônicos. O map of the world (mapa do mundo, ver Figura 1) remonta a 700 ou 500 anos a.C.

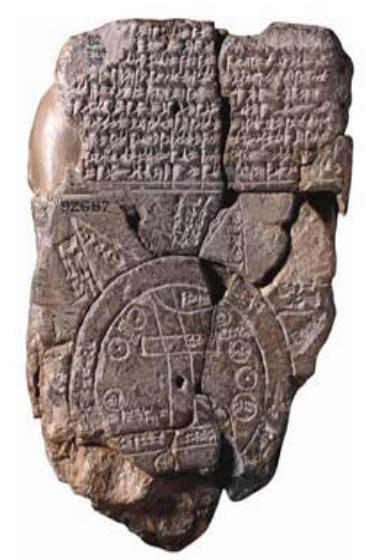

Figura 1 - O chamado "Mapa do Mundo", uma das mais antigas representações espaciais, está exposto no The British Museum.

Fonte: Disponível em: <http://www.britishmuseum.org/explore/highlights/highlight_objects/me/ m/map_of_the_world.aspx>. Acesso em: 10 mar. 2010. 
Do mesmo modo, o GA-Sur (Figura 2), nome dado a outro pequeno artefato $(7 \mathrm{~cm} \times 7 \mathrm{~cm})$, representa a região entre os rios Tigre e Eufrates, na então Mesopotâmia, atual Iraque. Trata-se de um pedaço de argila cozida que remonta, aproximadamente, a 2500 e 2000 anos a.C.

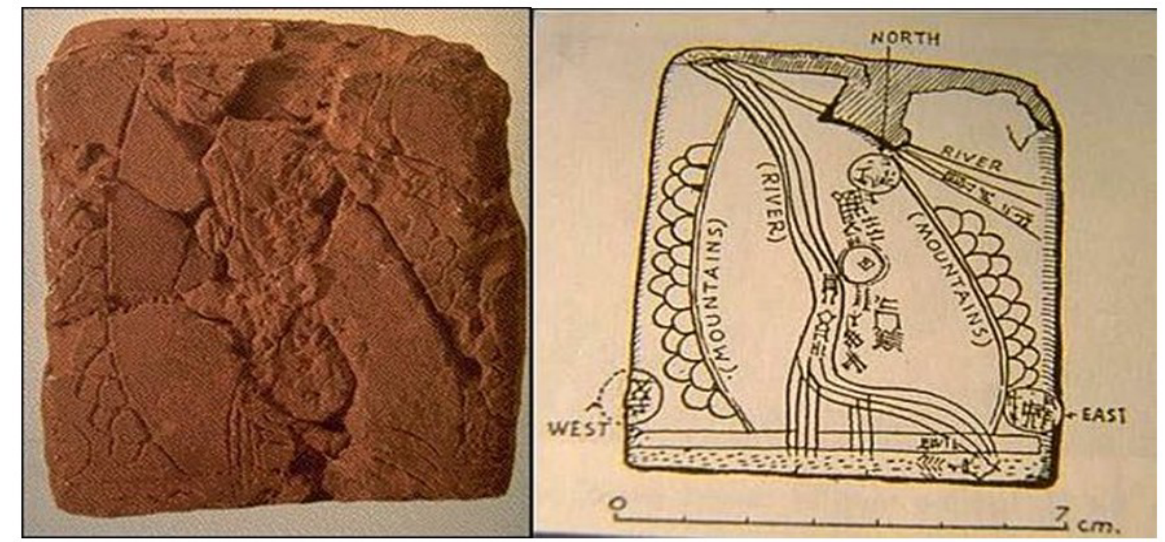

Figura 2 - O "GA-Sur", uma das representações espaciais mais antigas de que se tem notícia.

Fonte: Disponível em: <http://www.minerva.unito.it/storia/StoriaScienzeSperimentali/ Cartografia/Carto03.htm>. Acesso em: 27 fev. 2007.

Ainda outros exemplos podem ser dados. A figura 3 é uma foto em preto e branco de um mapa achado nas Ilhas Marshall:

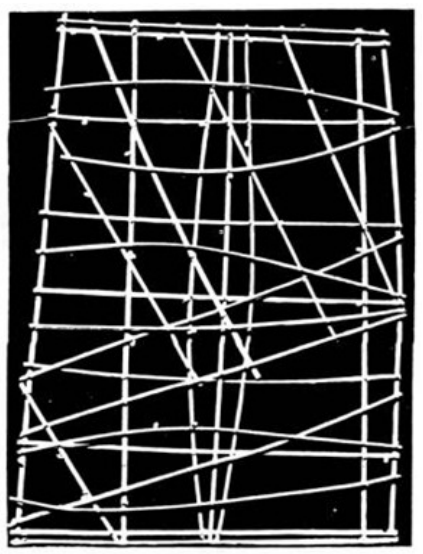

Figura 3 - Mapa das Ilhas Marshall. A localização relativa das ilhas pode ser percebida por meio do toque, pois as ilhas que constituem o arquipélago são representadas por pequenas conchas coladas às tiras de fibra.

Fonte: Disponível em: <http://www.ufrgs.br/museudetopografia/museu/museu/his_topo.html>. Acesso em: 10 mar. 2010. 
A figura 3 é um curioso mapa feito de tiras de fibra vegetal e representa a área oceânica do arquipélago formado pelas Ilhas Marshall, no Pacífico, a nordeste da Austrália. No mapa, as direções predominantes das ondas são representadas por linhas curvas e, destaque deve ser dado às ilhas que constituem o arquipélago, que podem ser percebidas através do tato, porque são feitas de conchas presas às tiras. Assim, para um autóctone de então, o entorno espacial que constituía o seu mundo conhecido podia ser facilmente reconhecido.

Fica claro que a representação espacial, a qual normalmente recebe $o$ nome de mapa, não precisa, necessariamente, ser feita em papel, podendo e de fato devendo, como será visto adiante, variar para atender a algumas demandas culturais:

\begin{abstract}
Quando percorremos a evolução dos sinais e da escrita, podemos constatar que, no passado, sua forma externa sofreu várias transformaç̧ões, estilizações e simplificações. Isso ocorreu principalmente devido aos meios de expressão usados ao longo dos séculos e que variavam conforme as mais diversas regiões geográficas. A utilização de materiais determinou a produção de ferramentas práticas, com as quais as informações podiam ser desenhadas e registradas. Desse modo, no Antigo Egito, por exemplo, os hieróglifos eram cinzelados em pedra e, mais tarde, escritos sobre papiro; no norte da Europa, as runas eram gravadas em madeira, ossos e pedras, enquanto na Mesopotâmia os sinais eram marcados em placas de argila, nas regiões ao sudeste, escoriados em largas folhas secas de palmeira. (FRUTIGER, 1999, p. 71)
\end{abstract}

A sociedade atual vive ainda, a despeito de todo o avanço tecnológico que encaminha à virtualidade, a cultura do papel. Isso, por si só, já renderia muito o que dizer quanto ao comprometimento ambiental que acaba provocando. Porém, como não é o objetivo do presente artigo enveredar por essas sendas, passemos adiante.

A própria virtualidade, acima citada, constitui-se, hoje, um problema. Não é de modo algum temerário afirmar que nunca na história da humanidade o contato com produtos cartográficos foi tão disseminado. Para os internautas, e.g., uma série de representações espaciais pode ser oferecida ao simples clique do mouse ou, caso preferiram, a própria realidade óptica sensível é disponibilizada, bastando que o usuário acesse o site do Google ${ }^{\mathrm{T}} \mathrm{m}$ maps ou outro. A figura 4 aduz muito bem o que estamos querendo mostrar. 


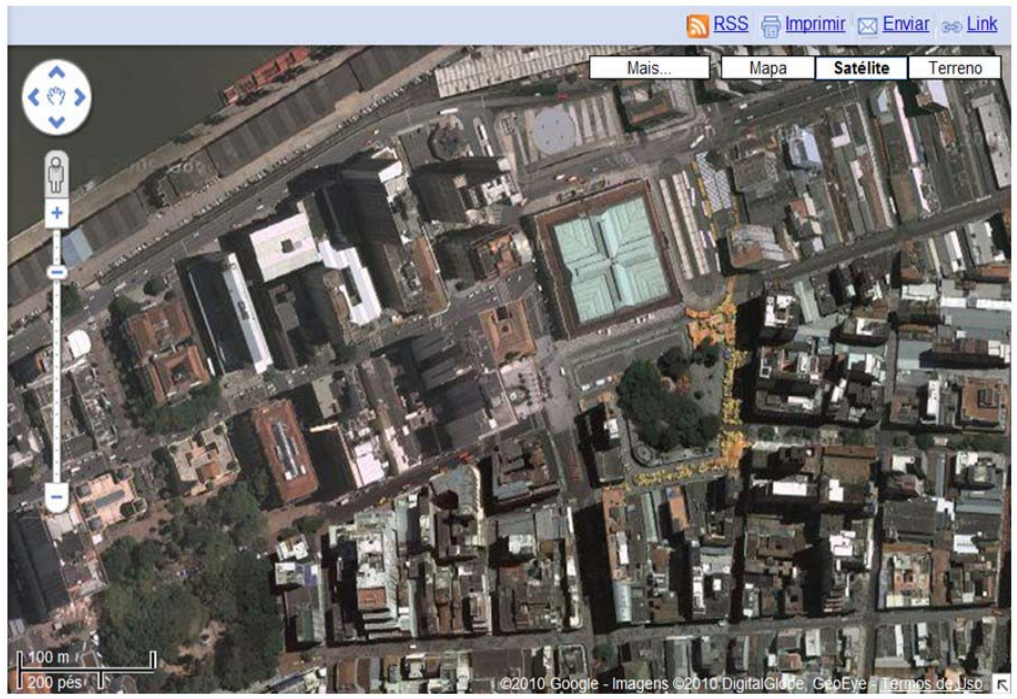

Figura 4 - Aspecto da cidade de Porto Alegre, tendo ao centro seu marco zero $\left(30^{\circ}\right.$ $01^{\prime} 40^{\prime S}$ e $\left.51^{\circ} 13^{\prime} 40^{\prime \prime} \mathrm{W}\right)$, na chamada "Praça Montevidéu", em frente à prefeitura. Imagem gerada pelo sensor DigitalGlobe, que a multinacional Google ${ }^{\mathrm{TM}}$ disponibiliza através do software Google Earth ${ }^{\mathrm{TM}}$ free ou do site Google maps. Fonte: Google maps. Disponível em: <http://maps.google.com.br/maps/ms?ie=UTF8\&hl=ptBR\&msa $=0 \& m s i d=113268917117113122028.0000011277172 d 5290 e a 3 \& t=k \&$ source=embed\& $\|=-$ 30.028213,-51.228551\&spn=0.00405,0.007843\&z=17>. Acesso em: 08 mar. 2010.

Na figura 4, é possível vislumbrar parte da cidade de Porto Alegre, como se o observador perfizesse sobre ela um voo de avião. A imagem, que é a de um sensor ${ }^{5}$ de alta resolução espacial ${ }^{6}$ (o DigitalGlobe tem uma resolução de $0,70 \mathrm{~m} \times 0,70 \mathrm{~m}$ ), permite que identifiquemos uma série de alvos na cena. É, na verdade, a realidade sensível aos olhos.

A figura 5, por sua vez, oferece ao internauta uma informação que não constava na figura 4. Ainda utilizando este exemplo do site Google ${ }^{T M}$ maps, é possível ler os nomes de ruas e de diversos locais ao selecionar a opção "mostrar nomes" (canto superior direito da figura 5), tais como: praças (Praça Montevidéu, Praça da Alfândega, Praça Quinze de Novembro, Praça Pereira) e equipamentos urbanos (Museu de Arte do Rio Grande do Sul, Porto Alegre City Hotel, bancos, chalés e lanchonetes). Esse tipo de informação só pode ser agregado à realidade sensível aos olhos graças às tecnologias atuais da inteligência, nas quais o próprio pensamento vai sendo alterado pela informática (LEVY, 1993). Dito de outro modo, à realidade sensível aos olhos é sobreposto um novo layer, uma camada de informações que não havia antes.

O nível da representação pode, ainda, chegar à máxima abstração, tal como exemplifica a figura 6. 


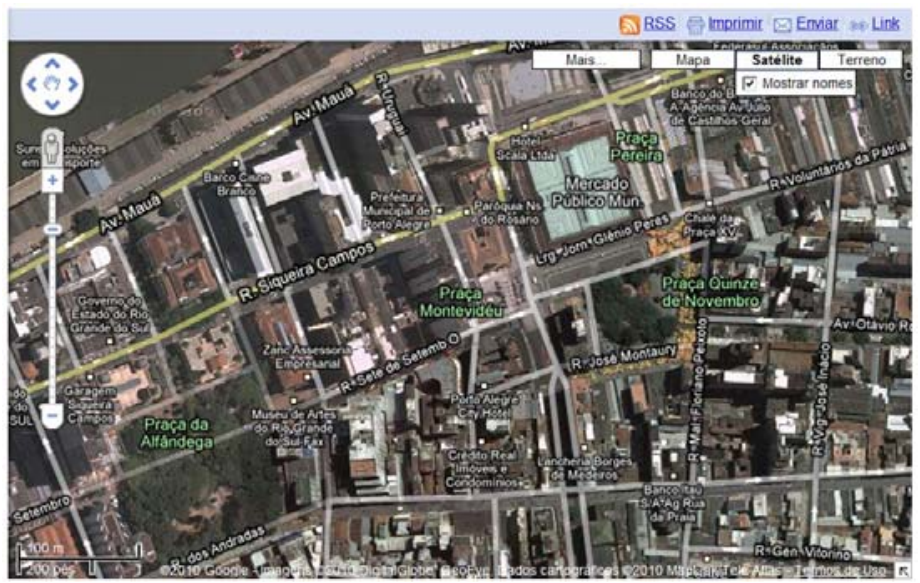

Figura 5 - Mapa temático da cidade de Porto Alegre, tendo ao centro o marco zero. Note-se que, na presente ilustração, há uma representação na qual os nomes das ruas estão postos diretamente sobre elas.

Fonte: Google maps. Disponível em: <http://maps.google.com.br/maps/ms?ie=UTF8\&hl=ptBR\&msa $=0 \& m s i d=113268917117113122028.0000011277172 d 5290$ ea3 $\& t=k \&$ source $=e m b e d \& \|=-$ 30.028213,-51.228551\&spn=0.00405,0.007843\&z=17>. Acesso em: 08 mar. 2010.

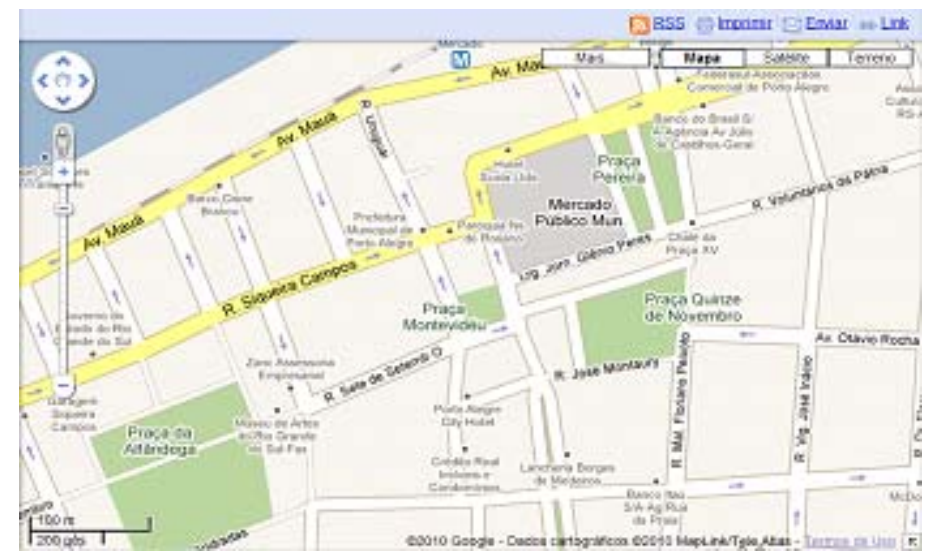

Figura 6 - Mapa temático da cidade de Porto Alegre que tem novamente ao centro o marco zero. Note-se que, na presente ilustração, há uma representação abstraída da realidade sensível aos olhos, na qual os quarteirões, ruas, avenidas e aparelhos urbanos foram substituídos por convenções planimétricas de cores diversas. Fonte: Google maps. Disponível em: <http://maps.google.com.br/maps/ms?ie=UTF8\&hl=ptBR\&msa $=0 \& m s i d=113268917117113122028.0000011277172 d 5290$ ea3\& $=k \&$ source $=$ embed\& $\|=-$ 30.028213,-51.228551\&spn=0.00405,0.007843\&z=17>. Acesso em: 08 mar. 2010.

A figura 6 representa a mesma área que as demais ilustrações (Figuras 4 e 5), porém faz isso em um nível de abstração maior. Nela não há nada da percepção visual empírica propriamente dita. Não vemos o espaço geográfico como normalmente veríamos do alto de um avião. Ao contrário, as realidades 
são substituídas por polígonos verdes, cinzas, amarelos e azuis, representando, respectivamente, praças, quadras, ruas e lago (lago Guaíba, no caso).

Problematizando o que foi visto até agora, a virtualidade pode até ser considerada a partir de uma postura otimista (como a adotada por Pierre Levy em seus diversos escritos), mas, ainda assim, passível de receber severas críticas, as quais serão, em maior ou menor grau, assumidas como pertinentes no presente artigo. Do mesmo modo, a cultura do papel, fortemente presente na nossa sociedade, acaba por aplainar as possibilidades de percepção e apreensão do Espaço. Obviamente não estamos, com isso, o que seria ingênuo, propondo uma Cruzada contra o papel e o virtual. No entanto, gostaríamos de chamar a atenção para o fato de que, do ponto de vista epistemológico, vivemos em um mundo cada vez mais dado à homogeneidade. Um mundo plano, onde não há lugar para desníveis altimétricos e para as rugosidades necessárias à percepção de algumas pessoas, como as pessoas cegas. ${ }^{7}$ A figura 7 , de uma maneira caricata, tenta dar conta desta argumentação.

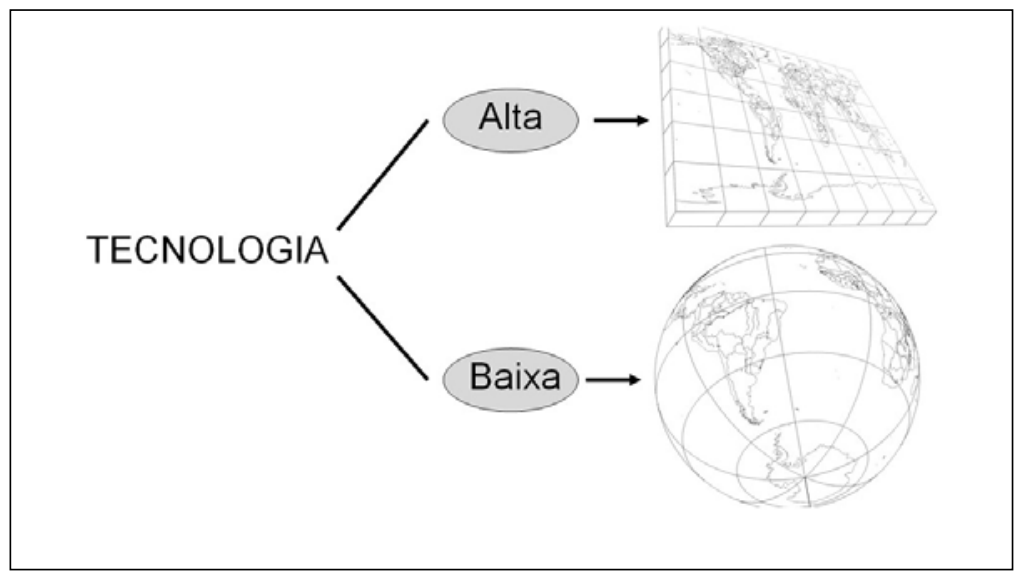

Figura 7 - A tecnologia promove um mundo cada vez mais plano. Fonte: Santos Júnior e Lahm (2008, p. 19).

Com base na figura 7, encaminhamos o próximo tópico do presente artigo. Friedman (2005), em seu controvertido livro, defende a ideia de que $o$ mundo é plano. Isso vai ao encontro da argumentação perseguida até agora: embora a tecnologia sirva como recurso de inclusão e atenda a uma série de necessidades especiais, ainda não é eficaz no que se refere ao sentido do tato. É imperativo, então, enquanto a realidade virtual proposta pela ficção científica não se torna um fato, um retorno ao concreto, um retorno às rugosidades e desnivelamentos que vão, de certo modo, contra o mundo tecnológico-aplainado atual. Neste cenário, a cartografia táti ${ }^{8}$ surge como possibilidade de construção concreta voltada à sensibilidade de estudantes que ainda necessitam conceber o mundo de uma forma intimamente ligada à pele. ${ }^{9}$ 


\section{A importância de saber ler mapas e a cartografia tátil como uma possibilidade}

No item anterior, procuramos deixar claro que, no mundo atual, tecnológico e aplainado, a possibilidade do tato, especialmente relativa à percepção do espaço geográfico, fica bastante comprometida. Para Mattelard (2000, p. 157), por exemplo, é possível até falarmos em "tecno-apartheid", visto que, no caso da Internet, e.g. " "[...] só $2 \%$ da população mundial estava em 1999 ligada à rede das redes". Tomando o nível de inclusão que é proporcionado para as pessoas com baixa visão, esse percentual é ainda menor. Poderíamos, aqui, pensar no Método Braille, mas ele não é capaz de dar conta de uma série de entendimentos necessários e inerentes à apreensão espacial. Desse modo, embora muitas palavras possam tentar descrever um relevo ou o contorno de um litoral, é o tato ao longo de um bloco sólido ou de uma linha que pode dar conta disso de um modo mais efetivo.

Emerge, então, que a popularização que verificamos no acesso aos produtos cartográficos, frequentemente disponibilizados pela mídia, seja para abordar questões relativas ao tempo meteorológico, seja para localizar regiões de conflitos no mundo, não é, de modo algum, universal.

Embora para o entendimento de um mundo cada vez mais globalizado, seja imprescindível o saber ler mapas, constatamos hoje, em muitos casos, que temos, na realidade, um enorme analfabetismo cartográfico. Monmonier (1996, p. 11) chama a atenção para isso e acusa a sua própria sociedade (a estadunidense) de ser, apesar de constituir uma das que mais utiliza mapas, cartograficamente analfabeta: "As a nation, Americans may not be as geographically literate as they should be, but they are fascinated by maps".

Vista dessa forma, a leitura cartográfica equipara-se à leitura formal e ao desenvolvimento da linguagem e, nesse sentido, emerge como atividade especificamente humana, constituída através do simbólico (cf. SMOLKA, 1989, p. 24) e que deve, portanto, ser treinada através do uso de materiais de aprendizagem estruturados que acompanhem o ritmo próprio dos alunos, sendo que, dentre estes, os culturalmente desfavorecidos merecem especial atenção (cf. AUSUBEL, NOVAK; HANESIAN, 1980, p. 253).

Para um entendimento não ingênuo do mundo, é fundamental a compreensão e a correta interpretação dos produtos cartográficos que são apresentados. Para tanto e especificamente com relação à educação espacial de pessoas com deficiência visual, o presente artigo propõe, como uma possível forma de trabalho em sala de aula, ${ }^{10}$ a utilização da cartografia tátil. Proporemos isso com base em uma geografia da percepção, meandrando, portanto, pela Fenomenologia, defendida, em diversos de seus trabalhos, por Claval (2001, 2007) e outros ainda, tais como: Merleau-Ponty $(1973,1990,2006)$, Masini (1988) e Moraes (1993). Valer-nos-emos, ainda, do trabalho de dois geógrafos americanos que, em virtude de uma geração tecnológica e informacional, ficaram esque- 
cidos por proporem o uso de experimentos nas aulas de Geografia. São eles: Chorley e Haggett (1974, p. 4), grandes defensores de modelos concretos na sala de aula, que argumentam que

\begin{abstract}
os modelos são aproximações altamente subjetivas no sentido de não incluírem todas as observações e medições associadas, mas, como tais, são valiosas em ocultar detalhes secundários e permitir o aparecimento dos aspectos fundamentais da realidade. Esta seletividade indica que os modelos têm graus variáveis de probabilidade e um alcance limitado de condições sobre as quais se aplicam. Os modelos de maior sucesso possuem uma alta capacidade de aplicação, uma extensa gama de condições sob as quais parecem apropriados. Com efeito, o valor de um modelo é muitas vezes diretamente relacionado ao seu nível de abstração. Apesar disso, todos os modelos têm necessidade de aperfeiçoamento constante e, à medida que surgem novas informações ou perspectivas da realidade e quanto maior o sucesso com que foi originalmente estruturado, mais provável que estes aperfeiçoamentos devam implicar na construção de um modelo diferente.
\end{abstract}

Destaque deve ser dado à necessidade de medidas que visem à inclusão social de pessoas com visão subnormal. Nesse sentido, destacamos desde já que o Grupo de Pesquisa "Geomática aplicada à educação", grupo devidamente certificado no CNPq e pela instituição (PUCRS), que é vinculado ao Laboratório e Tratamento de Imagens e Geoprocessamento (LTIG) da mesma Universidade, e do qual fizemos parte, vem se preocupando com tal inclusão e, para tanto, pesquisa possíveis formas de representação cartográfica, voltadas à interpretação a partir do tato.

"Como ler mapas sem compreender a sua construção?" Castrogiovanni e Costella (2006), autores da pergunta e professores do Departamento de Geografia da PUCRS, consideram o questionamento central. Eles defendem que um leitor de mapas, um educando alfabetizado cartograficamente, não é somente um decodificador, mas também um codificador. Por outros termos, é necessário que o educando seja capaz não somente de analisar, mas também de sintetizar as informações espaciais fornecidas na representação de um produto cartográfico. Não estamos, com isso, dizendo que as partes do todo não sejam importantes, porém, não estamos igualmente dizendo que o todo deva ser esquecido em detrimento de algumas das partes. Assim, em conformidade com a escola francesa de Geografia, emergem como categorias centrais a atividade, a relação, a conexão e a interdependência que possibilitarão a ligação das partes ao todo e do todo com as partes (BRUNHES, 1955). Nesse sentido:

Estar alfabetizado em Geografia significa relacionar espaço com natureza, espaço com sociedade, isto é perceber os aspectos econômicos, políticos e culturais, 


\begin{abstract}
entre outros, do mundo em que vivemos. Ler e escrever em geografia é ler o mundo de maneira que o aluno saiba situar-se (e não só localizar-se e descrever) e posicionar-se. Que assuma um posicionamento crítico com relação às desigualdades socioespaciais. (KAERCHER, 2004, p. 85)
\end{abstract}

Surge, então, como uma necessidade, o educar através da percepção espacial, pois esta, se bem feita, proporciona, paulatinamente, ao educando as competências e as habilidades que permitem a representação do espaço geográfico, que deve sempre ser concebido em sua totalidade complexa. ${ }^{11}$

Assim como é preciso estar familiarizado com a técnica da escrita e com o significado dos números para conseguir ler e fazer contas, é preciso familiarizar-se com os mapas para poder compreendê-los em toda sua complexibilidade. (ALMEIDA; LOCH, 2009)

As pessoas cegas, na maioria das vezes, não têm o acesso satisfatório a produtos cartográficos concebidos para o sentido do tato. Logo, muito do todo do Espaço é construído/concebido de uma forma bastante subjetiva e intrapessoal.

A criação do Método Braille deu certo acesso aos deficientes visuais que, por seu intermédio, puderam se inserir na cultura e nos variados campos do saber humano. Em princípio e durante muitos anos, este método se constituiu no mais valioso procedimento empregado no atendimento educacional aos cegos. Era base da instrução, aquisição de conhecimentos, do saber e da cultura intelectual, sob todas as suas formas (História, Filosofia, Psicologia, Teologia, Matemáticas, Filosofia, Literatura, Direito etc.). Os benefícios do sistema estenderam-se progressivamente à medida que as aplicações revelavam todas as suas potencialidades (LEITE, 2003).

Entretanto, como já foi aludido, nem todas as informações podem ser traduzidas pelo Método Braille. Ele não é suficiente para transcrever tudo. As representações do espaço, e.g., são impossíveis de serem transcritas eficiente e totalmente pelo mencionado sistema. A elaboração de modelos táteis é capaz de auxiliar na percepção do espaço de uma maneira mais efetiva. ${ }^{12}$

Assim, entendemos que ainda que uma maqueta, por exemplo, representa apenas uma fração do Espaço, moldando-o de uma maneira fragmentada, ela é útil a um reconhecimento em nível macro das feições geográficas. Deste modo, dentro do todo que é o planeta Terra, o cego tem a oportunidade de, através da pele, sentir os desníveis, as curvaturas e rupturas que a Natureza realmente apresenta. Isso encaminha um importante entendimento, que era amplamente defendido por Santos (1992): o espaço deve ser considerado como uma totalidade. Entretanto, através de análises, deve ser possível dividi-lo em partes e reconstituí-lo depois para um maior entendimento. A educação tem 
como objetivo promover a ampliação da visão de mundo e isso só ocorre, num segundo momento e num caminho inverso, a partir das partes em direção ao todo pois, conforme Freire (1996, p. 25), "Antes de me tornar um cidadão do mundo, fui e sou um cidadão de Recife".

A necessidade de dar acesso à Educação de qualidade aos portadores de deficiência visual faz crescer a demanda de profissionais qualificados para a construção desta forma de aprendizado - a da construção de elementos cartográficos especialmente confeccionados para o sentido do toque. Tal necessidade não deve ficar restrita à Geografia, pois, se o desenvolvimento do conhecimento geográfico tem relação com as demais áreas do conhecimento, qualquer outra ciência deveria aproveitar e, ao mesmo tempo, engajar-se a tais intentos. Assim, pensamos na Educação Infantil, visto que as disciplinas são apenas parcelas autônomas, mas não independentes do saber geral; portanto, a Educação Infantil pode e deve aproveitar-se de muitas das noções que nós estamos tentando construir aqui. É já no início do processo educativo que são transcendidas as realidades truncadas, as verdades parciais, mesmo não tendo, a priori, a ambição de filosofarmos ou de teorizarmos, acabamos por assim o fazer (SANTOS, 1992).

A percepção espacial, propriamente dita, está relacionada à forma como os sujeitos concebem o mundo. Consequentemente, as diferentes noções acerca da realidade merecem ser analisadas:

\begin{abstract}
O mundo onde os sujeitos vivem se dá num plano, num planeta específico: a Terra. O espaço, então, necessita ser averiguado. Por fim, a abordagem pedagógica e o entendimento que se tem sobre educação espacial devem ser apresentados. (SANTOS JÚNIOR, 2007)
\end{abstract}

Com vista nisso, defendemos que tal averiguação deva ser feita com base na realidade. Mesmo o método fenomenológico não nega a existência de uma realidade objetiva (MORAES, 1993). Acreditamos, aliás, que o processo educativo emerge com mais significação na medida em que se contemplam a realidade e a vivência do educando como pressupostos básicos, compreendendo, deste modo, os espaços mais locais, nos quais este educando vive e se locomove para, posteriormente, compreendê-los inseridos no todo global. Dessa forma,

em tempo de geografia, pode-se motivar os alunos a localizarem com precisão e criatividade a escola, o bairro, a região, ou a rua, de tal sorte que cada um descubra e reconstrua estas relações; pode-se imaginar que eles façam um mapa da localização ou construam um desenho simplificado da região. (DEMO, 2005, p. 23)

A cartografia tátil contempla não só os entendimentos epistêmicos acima aludidos, ela está de acordo com o escopo da Lei de Diretrizes e Bases 
da Educação no que diz respeito à educação inclusiva. Em seu artigo 58, a LDB assegura que a escola regular deve disponibilizar serviços de apoio especializado para atender às peculiaridades da clientela de educação especial. Quando não for possível a integração do aluno nas classes comuns de ensino regular, esse atendimento educacional deve ser feito em classes especializadas denominadas "salas de recursos". Por sua vez, o artigo 59 da mesma Lei, afirma que os sistemas de ensino assegurarão aos educandos com necessidades especiais, currículos, métodos, técnicas, recursos educativos e organização peculiar, para atender tais necessidades.

Na situação de ensino-aprendizagem de Geografia, os Parâmetros Curriculares orientam para a utilização de esquemas, maquetas, mapas e gráficos como recursos pedagógicos, bem como fotos, vídeos e desenhos para que os alunos possam compreender os fenômenos, os processos históricos e sociais, isto não só para alunos com necessidades especiais, mas também aos demais. Assim, em princípio, a construção de modelos táteis não deveria ser dirigida especificamente aos estudantes destituídos de visão. Julgamos lastimável verificar que, no fazer pedagógico de muitos professores (tanto da Geografia quanto das outras áreas e dos diversos níveis de ensino), o trabalho com o concreto foi há muito abandonado. Poucas vezes vemos, em sala de aula, as maquetas, as colagens, as caixas, caixinhas, palitos, barbantes etc. Para os professores de Geografia, isso seria ainda mais imputável, pois um professor de Geografia nunca deveria entrar em sala de aula desprovido de um globo ou um mapa (cf. SCHÄFFER, 2003).

\section{A cartografia tátil e sua utilização em sala de aula: uma experiência que deve ser partilhada pelos presentes autores}

A cartografia tátil é uma ramificação da Cartografia (LOCH, 2008). Preocupa-se com a confecção de mapas e instrumentos cartográficos para pessoas portadoras de deficiência visual. A cartografia tátil procura possibilitar uma percepção de mundo mais abrangente para os portadores de baixa visão e/ou cegos. Busca ampliar as possibilidades de percepção e facilitar a mobilidade espacial. Consequentemente, a cartografia tátil tem o potencial de se transformar numa poderosa ferramenta para o ensino de Geografia e demais ciências.

Frequentemente, na prática, a cartografia tátil esbarra na falta de políticas públicas efetivas de inclusão. A não obrigatoriedade de uma disciplina específica ou, ainda, a ausência de uma disciplina voltada para esse tipo de construção nos cursos de Licenciatura constitui um entrave factual. Em virtude dessa realidade, há o despreparo de professores de Geografia, que se formam sem saber utilizar uma linguagem acessível e concreta para (re)construir conceitos geográficos.

É fato que a falta de profissionais qualificados para (re)construir noções geográficas com educandos da educação especial e a respectiva importância do tema tornam a cartografia tátil uma necessidade premente. 
No início de nossa formação, ignorávamos também os aspectos que estão sendo defendidos aqui. Até que um de nós, após ter entrado em contato com professores e acadêmicos do Laboratório de Cartografia Tátil e Escolar (LABTATE), ${ }^{13}$ passou a estudar igualmente o tema. A partir do momento em que entendemos a dimensão do projeto idealizado pelo LABTATE, passamos a nos engajar em um projeto semelhante, desenvolvido em equipe pelo Laboratório de Tratamento de Imagens e Geoprocessamento (LTIG) da PUCRS.

Destarte, em 2008, desenvolvemos um método para levar a ideia da inclusão de deficientes visuais ao maior número possível de pessoas, pois sabemos que um dos fatores que mais contribuem para a manutenção de um preconceito é a própria falta de informação.

Aproveitando a estrutura do LTIG, onde desde 2007 já existe um projeto,${ }^{14}$ no qual são recebidos gratuitamente alunos de Ensino Fundamental e Médio para a aplicação de oficinas didático-pedagógicas ${ }^{15}$ pertinentes ao ensino de Geografia, foram direcionados recursos para compra de material e para a capacitação do pessoal, acadêmicos em Geografia da PUCRS.

O objetivo inicial era o de propor, por meio de um processo interativo e cooperativo, a construção de mapas táteis por educandos do Ensino Fundamental e Médio, que viessem a visitar o LTIG, bem como a capacitação de professores de Geografia e graduandos em Geografia da PUCRS que estivessem interessados em aprender a utilizar técnicas de confecção de mapas táteis.

Tendo como ponto de partida as bases cartográficas ou, ainda, os modelos táteis criados pela equipe do LABTATE, ${ }^{16}$ a equipe do LTIG/ PUCRS desenvolveu uma proposta diferenciada, que se baseia na conscientização da diferença que há entre a percepção de um cego e de um não-cego. A questão da inclusão também foi (re)construída com base na troca de experiências que passou a ser partilhada nas ocasiões em que as oficinas didático-pedagógicas eram executadas. Ao longo do processo, o grupo do LTIG pôde constatar, a partir das falas dos estudantes que participaram das atividades, que também 0 raciocínio lógico e a coordenação motora eram trabalhados à medida que as maquetas e os mapas táteis iam sendo construídos.

Na prática, as atividades aconteceram da seguinte forma: de posse do material necessário para elaboração dos mapas, os estudantes que estavam em visita ao LTIG passavam a construir diferentes produtos cartográficos táteis. Para tanto, o conteúdo, a matéria cartográfica e geográfica a ser trabaIhada era adequada aos respectivos níveis de desenvolvimento dos educandos. Por outras palavras, a série/ano letivo em que se encontravam os estudantes era levada em consideração, e o conteúdo geográfico era dimensionado segundo esse nível cognitivo. 
Desse modo, as atividades de colagem, nas quais eram delimitadas todas as áreas e limites dos mapas, o que era feito através de barbantes, folhas, palitos e outros recursos, iam sendo feitas de acordo com os conhecimentos formais preestabelecidos e com base nas mais variadas temáticas.

A construção do título, da legenda, da orientação e dos outros componentes de um mapa eram inscritos conforme o Método Braille, com as suas respectivas superfícies sensíveis ao tato, uma vez que que eram compostas por diferentes materiais de diferentes texturas e rugosidades e, para isso, cumpre dizermos, o reglete foi fundamental.

É importante destacar que, em determinadas fases da confecção, o professor assume papel de suma importância na mediação do processo, pois questões como inclusão, percepção, detalhe, rigidez, rugosidade, maleabilidade, etc. devem ser problematizadas. Ou seja, o educador deve instigar os educandos a teorizar acerca das possíveis percepções relacionadas às representações sensíveis dos mapas, o que, futuramente, poderá ser muito útil num ensino especial de excelência.

Digno de nota é que de forma recorrente se faz imperativa a (re)construção de conceitos básicos de cartografia, tais como: legenda, escala, orientação, lateralidade, convenções cartográficas, projeções, entre outros. Isso é imprescindível para que se promova, no momento da construção dos modelos, produtos cartográficos mais bem elaborados e contextualizados, segundo as necessidades específicas que têm de ser comunicadas através de cada representação.

No momento da construção dos produtos, por intermédio do processo participativo de construção, os mapas passam a assumir uma significação relevante e coerente com cada estádio cognitivo, visto que são construídos de forma colaborativa, permitindo a emergência de significâncias associadas a finalidades práticas. Por outras palavras, o produto cartográfico tátil que se está produzindo deve ser realmente útil para a vida dos alunos, pois só assim eles passarão a perceber de forma envolvida o espaço que ali está representado:

\begin{abstract}
O espaço construído resulta as histórias das pessoas, dos grupos que nele vivem, das formas, como trabaIham, como produzem, como se alimentam e como fazem usufruto do lazer. Isto resgata a questão da identidade e a dimensão de pertencimento. É fundamental, neste processo, que se busque reconhecer os vínculos afetivos que ligam as pessoas aos lugares, às paisagens e tornam significativo o seu estudo. (CALLAI, 2000 apud CASTROGIOVANNI, 2000, p. 84)
\end{abstract}

O que está sendo defendido aqui é que, de fato, as representações táteis podem e devem explorar o bairro, a cidade, as localidades pelas quais passa e se locomove o estudante que as está construindo. Deste modo, a esco- 
la, a padaria da esquina, a lomba que se sobe e/ou se desce para ir à praça e à própria casa do estudante emergem como formas significativas, representadas agora pela mão do próprio educando, que as vive de forma diversa em seu cotidiano.

Tínhamos em mente, após terem sido concluídos os mapas, a consecução de uma série de objetivos específicos. Por outros termos, na segunda fase do projeto, idealizavámos uma oficina didático-pedagógica itinerante, na qual os produtos táteis seriam levados às escolas especializadas no ensino de deficientes visuais. Intentávamos doar às escolas especializadas todo o material produzido ao longo do projeto. Esta etapa, porém, ainda não foi levada a cabo.

\section{Resultados parciais}

Como resultados parciais, foram produzidos mapas e globos táteis, confecções que correspondem ao período de capacitação da equipe do LTIG e de visitas de algumas escolas ao mesmo laboratório, conforme podemos observar nas figuras 8, 9, 10 e 11 .

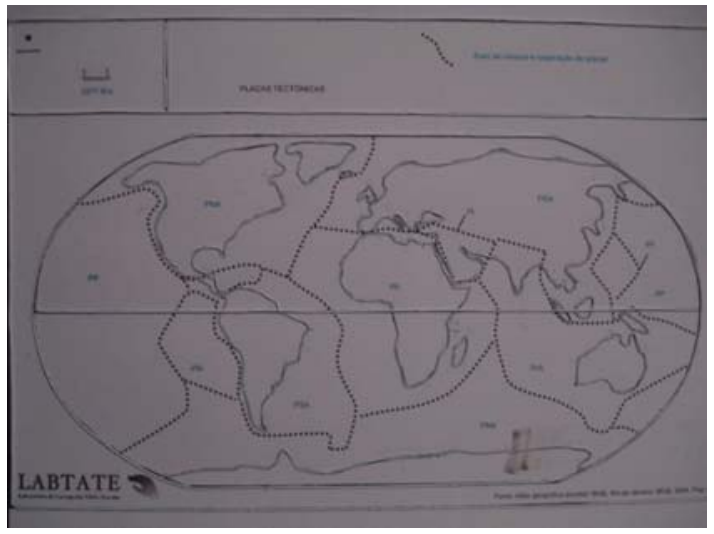

Figura 8 - Mapa-múndi com os limites entre as placas tectônicas. Elaborado com os recursos do barbante, da cola e da cartolina, buscando a sensibilidade tátil. Fonte: Arquivo do LTIG. 
Cleomar G. de Oliveira - Donarte N. dos Santos Júnior - Regis Alexandre Lahm

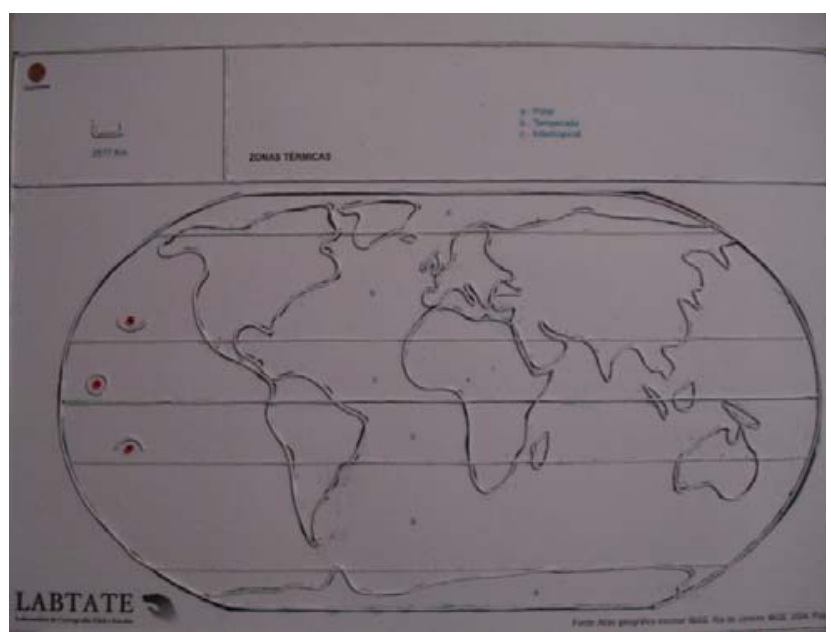

Figura 9 - Mapa-múndi com as zonas climáticas. Elaborado a partir dos recursos do barbante, da cola e da cartolina, visando a sensibilidade ao tato.

Fonte: Arquivo do LTIG.

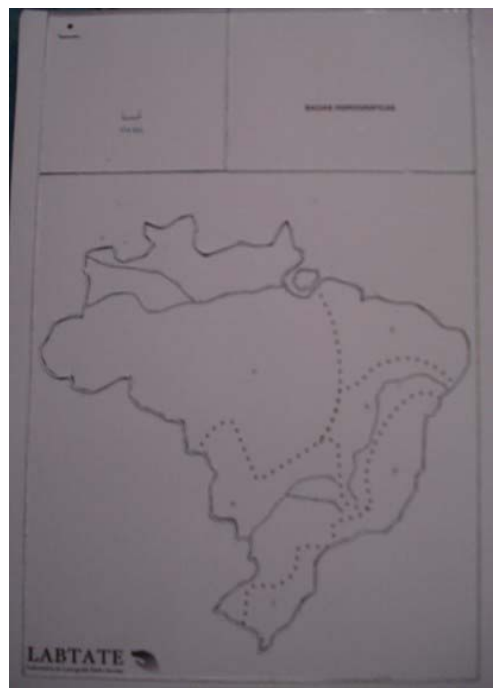

Figura 10 - Mapa do Brasil com os limites entre as bacias hidrográficas. Feito com barbantes, cola e cartolina, com vistas ao tato.

Fonte: Arquivo do LTIG. 


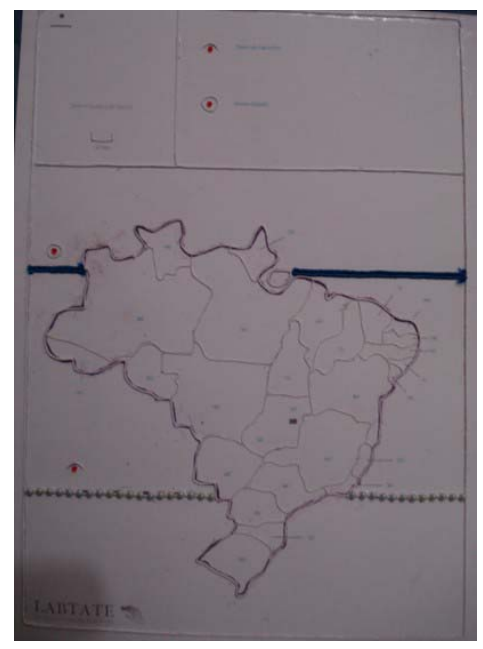

Figura 11- Mapa do Brasil com os limites entre as Unidades da Federação. Confeccionado com fios de barbante, cola e cartolina, objetivando a percepção por meio do toque.

Fonte: Arquivo do LTIG.

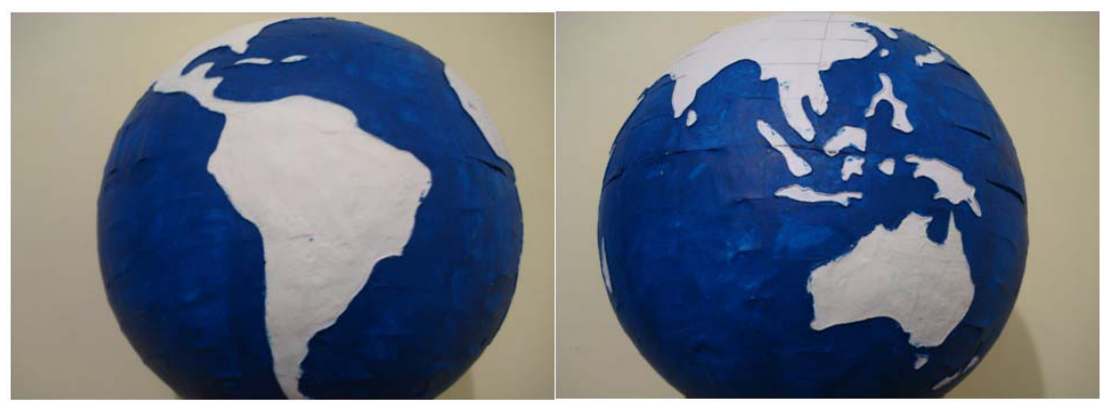

Figura 12 - Globo tátil com destaque para a conformação física dos continentes. Construído com uma esfera de isopor de $50 \mathrm{~cm}$ de diâmetro, papel sulfite de alta gramatura com a base dos continentes, e, para oferecer percepção tátil, fios de barbante.

Fonte: Arquivo do LTIG.

\section{Considerações finais}

A disponibilidade de materiais destinados ao ensino de cegos, obtidos através de processos de construção participativa, acaba por se transformar em ação concreta que colabora na instauração de uma verdadeira inclusão, visto que, entre outras coisas, no momento em que os educandos da Educação Básica são instigados a pensar a respeito da existência de pessoas que percebem o mundo de maneira diversa da deles, é-lhes dada a possibilidade de reco- 
nhecer tal alteridade e de agir no sentido de dirimir preconceitos e cristalizações sociais vigentes.

Aos professores e acadêmicos envolvidos no projeto, as ações levadas a cabo ao longo do seu desenvolvimento proporcionaram o observar e o agir por uma Geografia mais crítica e humana, pois, além de tais profissionais e estudantes entrarem em contato com conceitos básicos de cartografia, foi-Ihes permitido uma maior descentração e um exercício intersubjetivo dialógico, o que os encaminhou para uma percepção voltada à alteridade que foi, no decorrer do processo, sempre comunicada e sensibilizada através do tato e do diálogo.

Cumpre dizermos que a cartografia tátil é ainda pouco divulgada e pouco utilizada como recurso didático. Esse fato é verificado mesmo dentro de instituições dedicadas à educação especial e, muito mais, nas Instituições de Ensino Superior. Nesse sentido, ainda que possa parecer insipiente, a Pontifícia Universidade Católica do Rio Grande do Sul, através do Laboratório de Tratamento de Imagens e Geoprocessamento (LTIG), está dando um passo que acreditamos ser importante no processo de formação de professores qualificados para lidar com o concreto tátil e espacial, algo extraordinário para a educação espacial e para a educação cartográfica de portadores de deficiência visual.

É mister salientar que os modelos táteis desenvolvidos foram implementados com alunos de graduação do curso de Geografia da PUCRS, vinculado ao grupo de pesquisa Geomática aplicada à educação, na linha de pesquisa cartografia tátil. Os resultados parciais desta implementação são promissores. A importância da publicação deste artigo vislumbra a possibilidade de futuras partilhas com educadores interessados na cartografia tátil, abrindose, assim, a possibilidade de intercâmbios, contribuições e parcerias.

\section{Referências}

ALMEIDA, Luciana Cristina de; LOCH, Ruth Emília Nogueira. Iniciando a alfabetização cartográfica. Extensio: R. Eletr. de Extensão, v. 6, n. 7, jul. 2009. Disponível em: < http://www.periodicos.ufsc.br/index.php/extensio/article/view/ 10927/10434 > . Acesso em 10 jun. 2010.

AUSUBEL, David P.; NOVAK, Joseph D.; HANESIAN, Helen. Psicologia educacional. 2. ed. Rio de Janeiro: Interamericana, 1980. 625 p.

BACHELARD, Gaston. A formação do espírito científico: contribuição para uma psicanálise do conhecimento. Rio de Janeiro: Contraponto, 1996. 314 p.

BRASIL. Ministério da Educação e do Desporto, Secretaria da Educação Especial. Subsídios para a formulação da política nacional de educação especial. Brasília, 1993.

BRUNHES, Jean. Geografía humana. 2. ed. Barcelona: Juventud, 1955. 312 p. 
CALLAI, Helena Copetti. In. CASTROGIOVANNI, Antonio Carlos (Org.). Ensino de Geografia: práticas e textualizações no cotidiano. Porto Alegre: Mediação, 2000.

CASTROGIOVANNI, Antônio Carlos; COSTELLA, Roselane Zordan. Brincar e cartografar com os diferentes mundos geográficos: a alfabetização espacial. Porto Alegre: EDIPUCRS, 2006.

CASTROGIOVANNI, Antonio Carlos (Org.). Ensino de Geografia: práticas e textualizações no cotidiano. Porto Alegre: Mediação, 2000.

CHORLEY, Richard J.; HAGGETT, Peter. Modelos integrados em Geografia. Tradução Arnaldo Viriato de Medeiros. Rio de Janeiro: Livros Técnicos e Científicos; São Paulo: Ed. da USP, 1974.

CIRNE-LIMA, Carlos R. V. Depois de Hegel: uma reconstrução crítica do sistema neoplatônico. Caxias do Sul: EDUCS, 2006.

CLAVAL, Paul. O papel da Geografia Cultural na compreensão da ação humana. In. ZENY, Rosendhal; CORRÊA, Roberto Lobato. Matrizes da Geografia Cultural. Rio de Janeiro: Ed. da UERJ, 2001, p. 47-56.

Geografia Cultural. 3. ed. Tradução Luiz Fugazzola Pimenta e Margareth de Castro Afeche Pimenta. Florianópolis: UFSC, 2007.

DEMO, Pedro. Educar pela pesquisa. 7.ed. Campinas,SP: Autores Associados, 2005.

FREIRE, Paulo. Pedagogia da autonomia: saberes necessários à prática educativa. 7. ed. São Paulo: Paz \& Terra, 1996.

FRIEDMAN, Thomas L. O mundo é plano: uma breve história do século XXI. Rio de Janeiro: Objetiva, 2005.

FRUTIGER, Adrian. Sinais e símbolos: desenho, projeto e significado. São Paulo: Martins Fontes, 1999.

GOMES, Débora Marques. DST/AIDS e deficiência: um estudo sobre a vulnerabilidade de pessoas com deficiência visual. Relatório de Pesquisa de Conclusão de Curso (Faculdade de Filosofia). Faculdade de Psicologia, UNISUL, Palhoça, 2009. Disponível em: < http://inf.unisul.br/ psicologia/wp-content/ uploads/2009/07/debora.pdf>. Acesso em: 27 abr. 2010.

GOULART, Lígia Beatriz. Dificuldades para aprender Geografia: uma proposta de oficina de zona de desenvolvimento proximal. 1993. 174 f. Dissertação (Mestrado em Educação), Faculdade de Educação, PUCRS, Porto Alegre, 1993.

HAMMES, Care Cristiane. O desafio de uma perspectiva interdisciplinar na construção pedagógica do conhecimento geográfico. La Salle, Canoas, v. 12, n. 1, p. 7-20, jan./jun. 2007. 
KAERCHER, Nestor André. Ler e escrever a geografia para dizer a sua palavra e construir o seu espaço. In: NEVES, lara Conceição Bitencourt et al. Ler e escrever: compromisso de todas as áreas. 6. ed. Porto Alegre: Ed. da UFRGS, 2004. p.73-85.

KOSÍK, Karel. Dialética do concreto. Tradução Célia Neves e Alderico Toríbio. 4. ed. Rio de Janeiro: Paz e Terra, 1976.

LDB. Lei n. 9394/96. 2. ed. [Porto Alegre]: FETEE-SUL, 1996.

LEITE, Cristiane das Graças. A alfabetização de adultos portadores de deficiência visual. Revista Benjamim Constant, Rio de Janeiro, n. 24, abr. 2003. Disponível em: <http://200.156.28.7/Nucleus/media/common/ Nossos_Meios_RBC_RevAbr2003_Artigo_1.rtf>.Acesso em : 15 jun. 2010.

LÉVY, Pierre. As tecnologias da inteligência: o futuro do pensamento na era da informática. Rio de Janeiro: Editora 34, 1993.

LIPOVETSKY, Gilles. Os tempos hipermodernos. São Paulo: Barcarolla, 2005. $129 \mathrm{p}$.

LOCH, R. Cartografia tátil: mapas para deficientes visuais. Portal da Cartografia, América do Norte, 113082008.

LUFT, E. The origin of wealth: evolution, complexity and the radical remaking of economics (resenha). Filosofia Unisinos, v. 9, p. 180-182, 2008.

MASINI, Elcie F. Salzano. Enfoque fenomenológico de pesquisa em educação. Psico, Porto Alegre, v. 16, n. 2, p. 150-156, 1988.

. Algumas noções sobre fenomenologia para o psicólogo escolar. Psico, Porto Alegre, v. 16, n. 2, p. 157-170, 1988.

MATTELARD, Armand. A comunicação representa um novo horizonte das utopias totalizantes, incorporando a aposta do "progresso infinito". In: O novo estado do mundo: 80 ideias-força para entrar no século XXI. Porto: Campo das Letras, 2000.

MERLEAU-PONTY, Maurice. Ciências do homem e fenomenologia. São Paulo: Saraiva, 1973.

O primado da percepção e suas conseqüências filosóficas. Campinas: Papirus, 1990. 2006.

Fenomenologia da percepção. 3. ed. São Paulo: Martins Fontes,

MONMONIER, Mark. How to lie with maps. 2. ed. Chicago: The University of Chicago Press, 1996.

MORAES, Roque de. Fenomenologia: uma introdução. Educação, Porto Alegre, v. 16, n. 24, p. 15-24, 1993. 
MOREIRA, Ruy. Para onde vai o pensamento geográfico?: por uma epistemologia crítica. São Paulo: Contexto, 2006.

MORENO, Cláudio. O prazer das palavras: etimologia e mitologia. Zero Hora. Porto Alegre. 13 fev. 2010. Caderno Cultura, p. 7. Disponível em: <http:// zerohora. . licrbs.com. br/zerohora/jsp/default2.sp?uf=1\&local=1\&source=a 2807919.xml\&template=3916. dwt\&edition=14105\&section=1029 >. Acesso em: 14 fev. 2010.

OKA, Cecília M. Mapas táteis: são necessários? In: CONGRESSO BRASILEIRO DE EDUCAÇÃO DE DEFICIENTES VISUAIS, 9., 1999, Espírito Santo. Anais..., novembro de 1999

SANT'ANNA, Ilza Martins. Recursos auxiliares do ensino: oficina pedagógica numa perspectiva construtivista. Porto Alegre: Caravela, 1995.

SANTOS, Milton. Espaço e método. 3. ed. São Paulo: Nobel, 1992.

SANTOS JÚNIOR, Donarte Nunes dos. Geografia do espaço percebido: uma educação subjetiva. 2007. 280 f. Dissertação (Mestrado em Educação em Ciências e Matemática)-Faculdade de Física, PUCRS, Porto Alegre, 2007. Disponível em: <http://tede.pucrs.br/tde_busca/arquivo.php?codArquivo=974>. Acesso em: 08 mar. 2010.

SANTOS JÚNIOR, Donarte Nunes dos; LAHM, Regis Alexandre. A tecnologia: algumas reflexões socioespaço-temporais. para onde!? (UFRGS), v. 1, p. 8-27, 2008. Disponível <hppt://www6.ufrgs.br/seerpraonde/ojs/artigos/ Edicoes_anteriores/Revista_n03.pdf>. Acesso em 25 jul. 2009.

SCHÄFFER, Neiva Otero et al. Um globo em suas mãos: práticas para sala de aula. Porto Alegre: Ed. da UFRGS, 2003.

SMOLKA, Ana Luiza Bustamante. A atividade da leitura e o desenvolvimento das crianças: considerações sobre a constituição de sujeitos leitores. In. SMOLKA, Ana Luiza Bustamante et al. Leitura e desenvolvimento da linguagem. Porto Alegre: Mercado Aberto, 1989, p. 23-42.

. A Dinâmica discursiva no ato de escrever: relações oralidade-escrita. In. SMOLKA, Ana Luisa; GÓES, Maria Cecília Rafael de. A linguagem e o outro no espaço escolar: Vygotsky e a construção do conhecimento. 5. ed. Campinas: Papirus, 1996, p. 33-51.

. Esboço de uma perspectiva teórico-metodológica no estudo de processos de construção de conhecimento. In. SMOLKA, Ana Luisa; GÓES, Maria Cecília Rafael de. A significação nos espaços educacionais: interação social e subjetivação. 5. ed. Campinas: Papirus, 1996, p. 29-46.

TAYLOR, D. R. F. Uma base conceitual para a Cartografia: novas direções para a era da informação.Tradução de Regina Vasconcellos. Caderno de Textos Série Palestras, São Paulo: LEMADI- Depto. Geografia-FFLCH-USP, Ano I, n. 1, p.11-19, ago. 1992. 
VASCONCELLOS, R. Tactile mapping design and the visually impaired user. In: Wood, C. \& Keller, P. (Eds). Cartographic design: theoretical and pratical perspectives. New York: John Wiley \& Sons, 1996. p. 91-102.

\title{
VASCONCELLOS, Celso dos Santos. Construção do conhecimento em sala de aula. São Paulo: Libertad, 1999.
}

VIEIRA, Elaine. Grupo-oficina de ensino de Matemática: história de um percurso e prospectivas. 1992. 210 f. Dissertação (Mestrado em Educação)Faculdade de Educação, PUCRS, Porto Alegre, 1992.

167-172, 1993.

Por que oficinas pedagógicas? Educação, Porto Alegre, v. 16, n. 24, p.

\author{
VIEIRA, Elaine, VOLQUIND, Léa. Oficinas de ensino: O quê? Por quê? Como? \\ Porto Alegre: EDIPUCRS, 1996.
}

\begin{abstract}
Notas
1 Utilizaremos o termo "produto(s) cartográfico(s)" sempre que quisermos fazer referência às representações do Espaço, sejam elas mais ou menos precisas do ponto de vista geodésicocartográfico. Como não é o objetivo do presente artigo, não discorreremos acerca das diferenças e semelhanças existentes entre mapas, cartas, maquetas (do francês, maquete) etc.

2 O termo "Espaço" será grafado em letra maiúscula, porque o Espaço, que é o objeto de estudo da Ciência Geográfica, merece destaque neste artigo.

${ }^{3}$ Nesse sentido convém memorar que Atlas, titã que conforme a mitologia grega travou luta contra Zeus, só teve seu nome associado às compilações de mapas graças à publicação de uma coleção de cartas feitas no século XVI, por Gerardus Mercator (1512-1594), cartógrafo belga. A primeira edição de tal livro continha na capa uma gravura do titã que, em razão de ter perdido a batalha contra Zeus, foi condenado a carregar a Terra às costas. Por este motivo, desde aquela época, utiliza-se o termo Atlas para designar toda e qualquer coleção de mapas. O próprio Mercator, já se referia às suas coleções cartográficas com o nome do titã mitológico (cf. MORENO, 2010).

${ }^{4}$ Videntocentrismo, conforme Gomes (2009), em trabalho orientado pelos professores doutores Leandro Castro Oltramari e Adriano Henrique Nuernberg, é um neologismo que se refere ao fato de a sociedade atual estar erigida para pessoas que enxergam: uma sociedade centrada no vidente.

${ }^{5}$ Cabe lembrarmos que o sensor é o aparelho óptico-eletrônico que, de fato, detecta e registra, sob a forma de uma imagem, a reflectância (que é a propriedade intrínseca de um alvo, que pode variar entre 0 e 1 e que, posteriormente, é convertida em radiância (que é a propriedade intrínseca da "radiação eletromagnética", que tem sua variação ao longo do ano, conforme as estações)) proveniente de um alvo na superfície terrestre ou em sua atmosfera. $O$ satélite propriamente dito é tão somente a plataforma, o "invólucro" metálico que abriga o sensor. Assim, tecnicamente, a terminologia "imagem de satélite" não é estritamente correta, devendo, sugerese, ser substituída por "imagem orbital".

${ }^{6} \mathrm{~A}$ resolução espacial é uma medida de grandeza que corresponde ao tamanho da célula mínima de uma imagem, denominada de pixel (do inglês picture element).

${ }^{7}$ Embora conheçamos as gradações dadas pela Escala de Snellen e as recomendações subsidiadas e formuladas especialmente para as políticas nacionais de educação especial (BRASIL, 1993), para efeitos do presente texto, os termos "pessoa(s) cega(s)", "pessoa(s) com baixa visão", "pessoa(s) com deficiência visual" e "pessoa(s) com visão subnormal" serão considerados como equivalentes.

${ }^{8}$ Não temos um conceito fechado acerca do que seja, afinal, a cartografia tátil. Segundo nosso entendimento, uma maqueta (do francês maquete) pode ser inserida na chamada cartografia
\end{abstract}


tátil. Um bloco 3D que represente um relevo, por exemplo, também pode ser considerado como tátil e cartográfico. Ao final deste artigo, porém, aproximar-nos-emos cada vez mais de uma concepção geodésica e cartográfica estrita, sugerindo a inserção nos mencionados produtos cartográficos de legenda, escala, orientação, planimetria etc., e ofereceremos um conceito para o termo.

${ }^{9}$ Não desconhecemos as noções que se valem do pressuposto de que os processos psicológicos emergem graças à relação do modo de vida dos indivíduos em interação com a natureza social/semiótica da atividade mental destes mesmos indivíduos, aspecto que remonta certamente à linguagem, à subjetividade e à dialogia entre os elementos citados (cf. SMOLKA, 1996, p. 35; 1997, p. 29). Tal abordagem histórico-cultural emergirá no presente texto quando versar acerca das oficinas didático-pedagógicas. Por outros termos, entendemos que o retorno ao concreto é apenas um dos elementos que colaborará na construção do conhecimento que, por sua vez, se dará na interação entre os indivíduos na história. Assim, justificamos tal abordagem na medida em que considerarmos que há a necessidade de se perfazer um retorno ao mundo da vida, pois o mundo, conforme Merleau-Ponty (1973), não é aquilo que eu penso ser. Eu não possuo a totalidade das coisas, porque elas são inesgotáveis. Então, sem sermos empiricistas, defendemos um "retorno àquilo que ficou esquecido, encoberto pela familiaridade" (MASINI, 1988 , p. 150) e o concreto pode oferecer isso ao deficiente visual, ainda que não completamente, como já externamos. Deste modo, defendemos que o retorno ao concreto remonta àquilo que está estabelecido como critério e possibilita o questionamento e a vivência (ainda que diversa) relativos a tais fundamentos (cf. MASINI, 1988, p. 150).

${ }^{10}$ A expressão "formas de trabalho em sala de aula" foi tirada de Vasconcellos (1999, p. 83) quando escreve que: "O professor sabe que quem conhece é o aluno pela sua ação (ele não pode conhecer pelo aluno, por mais que se esforce ou goste do aluno). No entanto, enquanto organizador do processo de ensino-aprendizagem, o professor tem que ser o mediador desta ação. Na relação pedagógica, a atividade primeira, comumente, é do professor, não na perspectiva de ficar nele, mas de provocar, de propiciar a atividade do aluno". Notamos que o entendimento aqui exposto guarda íntima relação com as formas de trabalho adotadas pelo professor em seu fazer em sala de aula ou, ainda, nas atividades propostas aos educandos. As "oficinas" são, certamente, uma destas formas/atividades.

${ }^{11}$ Não é pretensão do presente artigo entrar na discussão acerca de o que é e do que não é a complexidade. No entanto, gostaríamos de manifestar que entendemos a complexidade de uma maneira bastante simples e pontual, em concordância com Luft (2008, p.181) quando diz: "Complexidade significa irredutibilidade algorítmica". Assim, por outros termos, complexidade é a impossibilidade de uma redução rápida que permite novamente a montagem do todo a partir do processo inverso. Nesse sentido, é possível dizermos, junto com Cirne-Lima (2006), que, depois de ter o relógio desmontado em cima da mesa, o que temos são apenas as peças do relógio, pois, ele mesmo, o relógio, não funcionará mais.

12 Obviamente sabemos que nem mesmo modelos táteis são capazes de proporcionar uma (re)construção totalmente adequada da realidade objetiva. Porém, entendemos que, representações táteis guardam certas vantagens indiscutíveis se comparadas ao Método Braille. Afinal, "[...] unicamente por ser inexato em algum aspecto pode um modelo representar seu original" (BLACK, 1962 apud CHORLEY e HAGGETT, 1974, p. 4). Não é perda de tempo insistirmos neste aspecto. Muitos epistemólogos da Geografia acabam por lançar novos paradigmas que, após emergirem no palco dessa ciência, são imediatamente adotados, despidos, entretanto, de sua devida crítica. Assim, por exemplo, o paradigma ecológico atualmente substitui a antiga forma de o homem conceber a natureza (MOREIRA, 2006). Já há muito, devem os geógrafos ver o mundo segundo a sua totalidade e a partir de uma dialética recursiva (KOSÍK, 1976; SANTOS, 1992). Contudo, entendemos que são muitas dessas teorizações que acabam por afastar os geógrafos, e, por conseguinte, os professores de Geografia de uma geografia da vida, prática, concreta e efetiva. O que estamos tentando dizer é que não ignoramos que "os instrumentos não são mais do que teorias materializadas" (BACHELARD, 1986, p. 16) e que os atuais estudantes hipermodernos (LIPOVETSKY, 2005) dispõem de uma série de diversidades midiáticas disponibilizadas pela infovia. Porém, ainda assim, são as "aproximações seletivas que, pela eliminação de detalhes acidentais, permitem o aparecimento de alguns aspectos fundamentais, relevantes ou interessantes do mundo real" (CHORLEY; HAGGETT, 1974, p. 4).

${ }^{13}$ O LABTATE é um laboratório especializado em cartografia tátil da Universidade Federal de Santa Catarina (UFSC). Em 2008, quando do "Encontro Regional de Estudantes de Geografia do 
Sul (EREGEO Sul)" (mais em: http://www.caligeo.ufsc.br/eregeo/), um dos autores (Cleomar Graef de Oliveira) participou de uma oficina ministrada pela equipe do referido laboratório. $\mathrm{Na}$ ocasião, a temática do encontro "A Geografia serve, em primeiro lugar, para quê(m)?" permeou as ações no sentido de sensibilizar para uma inclusão efetiva. Para ir além com relação às pesquisas do referido laboratório e demais trabalhos na área, sugerimos as seguintes leituras: Hammes (2007), disponível também em: http://www.labtate.ufsc.br; Oka (1999); Taylor (1992). ${ }^{14}$ O Laboratório de Tratamento de Imagens e Geoprocessamento (LTIG) da PUCRS conta com um projeto intitulado "Aplicação de Novas Tecnologias através de Oficinas Didático-pedagógicas: na busca da interatividade entre Comunidade e Universidade" que recebe, gratuitamente, escolas da Educação Básica para que os mesmos tenham contato com as tecnologias envolvidas no trabalho diário do geógrafo.

${ }^{15}$ A maioria dos teóricos que escrevem sobre oficinas, tais como, Vieira (1992), Goulart (1993), Vieira e Volquind (1996) e Sant'Anna (1995), prefere utilizar o termo "oficina(s) pedagógica(s)". No entanto, utilizaremos o termo "oficina(s) didático-pedagógica(s)". Segundo Vieira (1993, p. 197), "A palavra oficina representa o que os espanhóis chamam de 'taller'. A palavra 'taller' provém do francês 'atelier' e significa estudo, obra, oficina". Para saber mais sobre aplicação de oficinas pedagógicas, especificamente na geografia, ler: Goulart (1993, p. 38-50). Na prática, entendemos a oficina didático-pedagógica como sendo "[...] uma forma de ensinar e aprender, mediante a realização de algo feito coletivamente. Salienta-se que oficina é uma modalidade de ação. Toda oficina necessita promover a investigação, a ação, a reflexão; combinar o trabalho individual e a tarefa socializadora; garantir a unidade entre a teoria e a prática" (p. 11). Diante deste entendimento, é importante dizermos que, muito do que se lê atualmente, mesmo em revistas especializadas, mereceria ser chamado de "heresia" e não de oficina, pois, de fato e na prática, nada propõe de interativo e coletivo (cf. SANTOS JÚNIOR, 2007, p. 131).

${ }^{16}$ No site do LABTATE, na seção "Clique para baixar arquivos", é possível fazer o download de uma série de modelos de mapas táteis. Tais modelos vão desde a América até a Oceania, e são oferecidos em diversas temáticas, tai como: mapa físico, mapa de vegetação, mapa político, mapa de zonas térmicas, etc. Para ir além, acessar: http://www.labtate.ufsc.br/ ct_clique_p_baixar.html.

\section{Correspondência}

Cleomar Graef de Oliveira - Av. Ipiranga 6681, Prédio 05 - Sala 206, CEP 90619-900,

Porto Alegre / RS - Brasil.

E-mail: cleomar.oliveira@acad.pucrs.br; lahm@pucrs.br

Recebido em 25 de março de 2010

Aprovado em 23 de junho de 2010 